Shah, P.M., Amarasingham, R. \& OAkley, C.M. (1965) Haemodynamic effects of changes in blood volume in hypertrophic obstructive cardiomyopathy. Brit. Heart J. 27, 83.

Sharpex-Schafer, E.P. (1955) Effects of squatting on the normal and failing circulation. Brit. med. J. i, 693 .

Tobin, J.R., Blundell, P.E., GoOdrich, R.G. \& Swan, H.J.C. (1965) Induced pressure gradients across infundibular zone of right ventricle in normal dogs. Circulat. Res. $16,162$.

Tucker, R.B.K., Barlow, J.B., Zion, M.M. \& Gale, G.E. (1966) Hypertrophic obstructive cardiomyopathy in Johannesburg. Proceedings, Fifth World Congress on Cardiology, 1966, p. 197.

Vogelpoel, L., Nellen, M., Swanepoel, A. \& Schrire, V. (1959) The use of amyl nitrite in the diagnosis of systolic murmurs. Lancet, ii, 810.
White, R.I., Lewis, K.B. \& Criley, J.M. (1965) Nonobstructive nature of isoproterenol-induced left ventricular pressure gradients in dogs. (Abstract). Circulation, 32, suppl. 11, 11 .

Wigle, D.E., Chrysohou, A. \& Lenkei, S.C.M. (1964) The effect of peripheral vasodilatation in muscular subaortic stenosis. (Abstract). Amer. J. Cardiol. 13, 144.

Wigle, D.E., Marquis, Y. \& Auger, P. (1967) Muscular subaortic stenosis. Initial left ventricular inflow tract pressure in the assessment of intraventricular pressure differences in man. Circulation, 35, 1100.

Wilson, W.S., Criley, J.M. \& Ross, R.S. (1967) Dynamics of left ventricular emptying in hypertrophic subaortic stenosis. Amer. Heart J. 73, 4.

\title{
A modified index of phosphate excretion
}

\author{
B. E. C. Nordin L. Bulusu \\ Medical Research Council Mineral Metabolism Research Unit, \\ General Infirmary, Leeds
}

THERE are several ways of looking at the excretion of phosphorus, or for that matter of any element in the urine. For certain purposes, it is most appropriate to consider the total daily or weekly excretion and relate it to the dietary intake and faecal output as part of a balance study, the object of which is to establish whether the subject is in negative or positive balance on a particular dietary intake. In the study of kidney stone disease, the important criterion is probably the concentration of the different phosphate ion species in the urine and these can be calculated from a knowledge of urinary $\mathrm{pH}$ and total phosphorus concentration (the organic phosphorus content of the urine being negligible). In relation to many other aspects of calcium and phosphorus metabolism, however, the physiological parameter of particular interest is the tubular reabsorption of phosphorus, both because it is a large factor in the regulation of the plasma phosphorus level and because it is under the control of the parathyroid glands.

There are various ways of assessing tubular reabsorption of phosphorus, the simplest being the measurement of phosphate clearance (which Is inversely related to tubular reabsorption) (Kyle, Schaaf \& Canary, 1958) and the most sophisticated the measurement of the maximum tubular reabsorptive capacity (Anderson \& Parsons, 1963). Between these extremes is the phosphate/creatinine clearance ratio which in- dicates the proportion of filtered phosphate that is not reabsorbed by the tubules; it tends to be raised in hyperparathyroidism and reduced in hypoparathyroidism (Milne, Stanbury \& Thompson, 1952 ; Nordin \& Fraser, 1954).

Unfortunately, the phosphate/creatinine clearance ratio is itself governed not only by tubular function but also by the filtered load of phosphorus itself since there is a very high correlation between the plasma phosphorus level and the phosphate/creatinine clearance ratio in normal subjects (Lambert, van Kessel \& Leplat, 1947). For this reason, Nordin \& Fraser (1960) suggested that any particular value of $C_{\mathrm{p}} / C_{\text {or }}$ should always be related to the plasma phosphorus level and that the extent to which the observed value differed from the predicted value could be used as a measure of tubular reabsorption of phosphorus. They called this value the phosphate excretion index, established the limits \pm 0.09 and showed that higher values were associated with states of hyperparathyroidism and low values with states of parathyroid insufficiency.

The general validity of the phosphate excretion index has since been confirmed. It is generally raised in primary hyperparathyroidism (Nordin \& Smith, 1965) and frequently also in the secondary hyperparathyroidism of osteomalacia (Nordin \& Fraser, 1960), renal failure and high phosphate feeding (Smith \& Nordin, 
1964) and reduced not only in hypoparathyroidism but in parathyroid suppression produced by calcium infusion (Nordin \& Smith, 1965) and phosphate deprivation (Nordin, 1961). However some criticism has been made of this calculation because a few normal values have been reported in primary hyperparathyroidism (Reynolds, Lanman \& Tupikova, (1960) and occasional high values in renal stone disease without hyperparathyroidism (Hodgkinson, 1963). The proportion of false negatives does not appear to be higher than with many other biochemical tests which are in constant use, but re-examination of the subject suggests that a better phosphate excretion index would be one which derived from the phosphorus excretion per $100 \mathrm{ml}$ of glomerular filtrate rather from the phosphate/ creatinine clearance ratio and this modification forms the subject of the present paper.

\section{Cases studied}

The analysis is based on the following material:

The normal and hypoparathyroid data of Nordin \& Fraser (1960).

The normal data of Harden, Harrison \& Alexander (1963).

The normal, renal stone and hyperparathyroid data of Edwards \& Hodgkinson (1965).

The hyperparathyroid data of Nordin (1964).

Unpublished data on fifty stone cases of our own studied in Leeds.

Unpublished data on a further five hypoparathyroid cases of our own.

This makes a total of ninety-five normal subjects, thirty-one cases of primary hyperparathyroidism, 100 cases of renal stone and ten cases of hypoparathyroidism, in addition to the original data of Lambert et al. (1947).

\section{Methods}

Since the data come from so many sources, various methods were used for determination of phosphate and creatinine in plasma and urine, details of which will be found in the original publications of the authors concerned. Our unpublished data are all derived from AutoAnalyzer measurements of phosphate and creatinine in plasma and urine (Nordin \& Smith, 1965).

\section{Calculations}

Since the phosphate/creatinine clearance ratio is the proportion of filtered phosphate that is not reabsorbed in the tubules, the product of this ratio and the plasma phosphorus concentration in $\mathrm{mg}$ per $100 \mathrm{ml}$ of plasma is the same as the phosphorus excretion per $100 \mathrm{ml}$ of glomerular filtrate (Thomas, Connor \& Morgan, 1959).

This can be expressed as follows:

$$
\mathrm{P}_{\mathrm{E}}=\frac{U_{\mathrm{p}} \times P_{\mathrm{cr}} \times P_{\mathrm{p}}}{P_{\mathrm{p}} \times U_{\mathrm{cr}}}
$$

where $U_{\mathrm{p}}$ and $P_{\mathrm{p}}$ and $U_{\mathrm{or}}$ and $\boldsymbol{P}_{\mathrm{cr}}$ represent the urinary and plasma concentrations of phosphorus and creatinine. This can be simplified to:

$$
\mathbf{P}_{\mathrm{E}}=\frac{U_{\mathrm{p}} \times P_{\mathrm{cr}}}{U_{\mathrm{cr}}}
$$

\section{Results}

Recalculation of the data of Lambert et al. (1947) (Fig. 1) showed that the regression of $P_{E}$

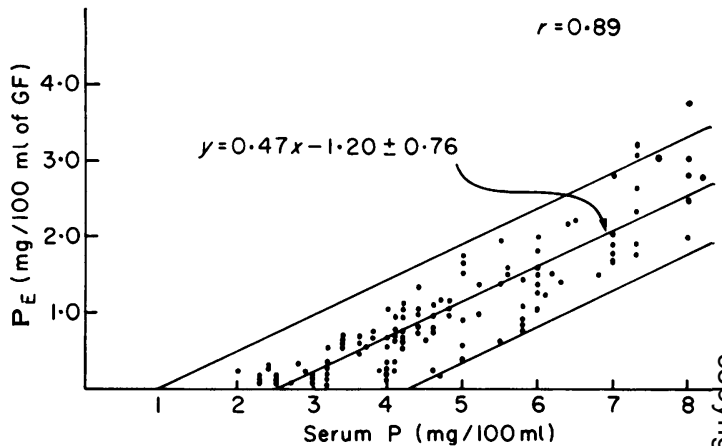

Fig. 1. The relation between serum phosphorus and phosphate excreted per $100 \mathrm{ml}$ of glomerular filtrate calculated from the infusion data of Lambert, van Kessel \& Leplat (1947).

on plasma $\mathrm{P}$ was highly significant $(r=0.89)$ and could be expressed as:

$$
P_{E}=0.47 P_{p}-1.2 \pm 0.76 \text { (95\% limits) }
$$

The relation between plasma phosphorus and $P_{E}$ in our normal subjects is shown in Fig. 2

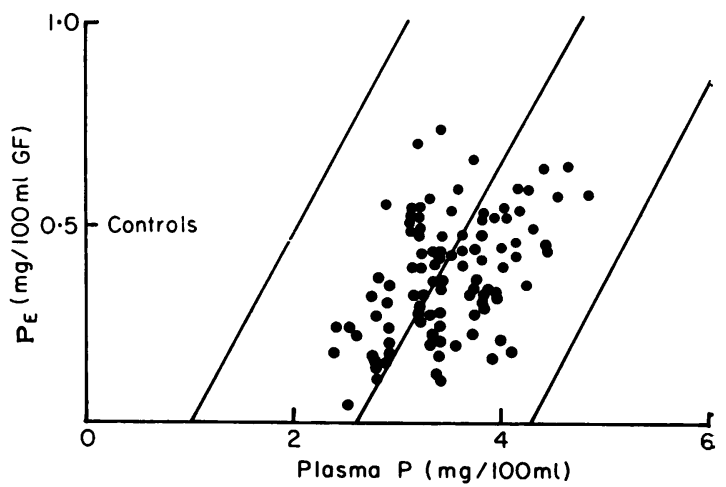

Fig. 2. The relation between plasma phosphorus and phosphate excreted per $100 \mathrm{ml}$ of glomerular filtrate in simultaneous random samples of plasma and urine obtained from ninety-five normal subjects. The regression lines are the same as in Fig. 1. 
and compared with the regression line and $95 \%$ limits from Fig. 1. It will be seen that all our normal data fall within the calculated limits. There is a highly significant positive correlation between $\mathrm{P}_{\mathrm{E}}$ and $\boldsymbol{P}_{\mathrm{p}}(r=0.39)$ although the calculated slope is less steep than that of Lambert et al. For convenience we have called the difference between the observed and predicted value of $P_{E}$ the index of phosphate excretion (IPE).

The IPE values of our normal subjects are shown in Fig. 3. The mean value was -0.044

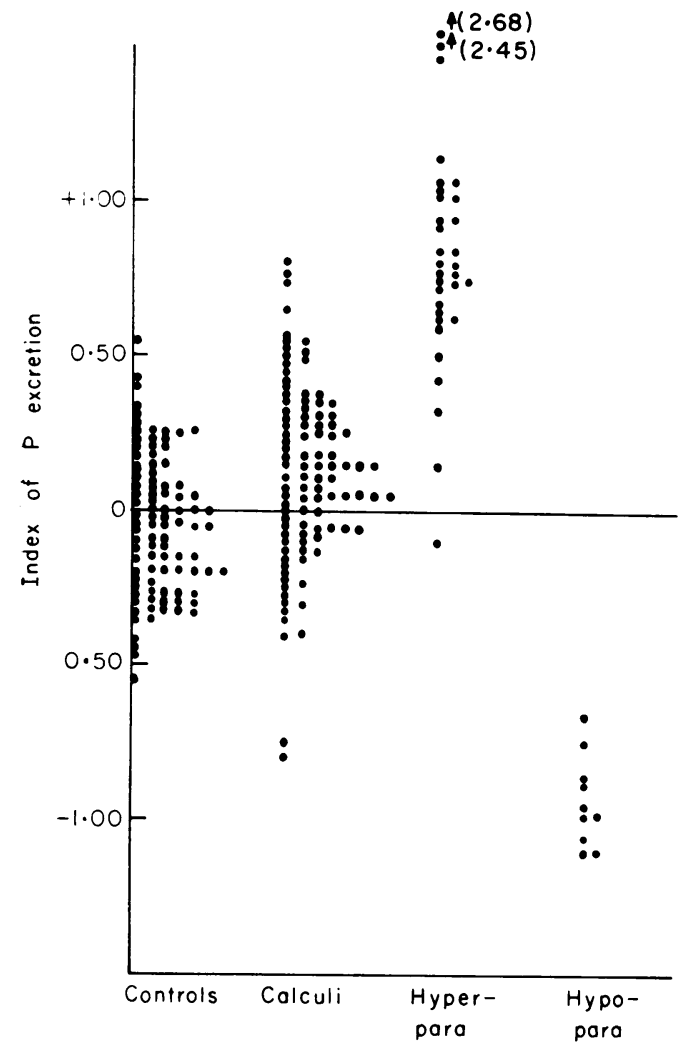

FIG. 3. Deviation of phosphate excretion per $100 \mathrm{ml}$ of glomerular filtrate from predicted mean values derived from the data in Fig. 1 showing the separation between normal, increased and decreased parathyroid activity. The suggested 'normal range' of this index of phosphate excretion is \pm 0.50 .

and the standard deviation $0 \cdot 226$. It will be noted that there is a slight tendency for our normal data to fall below the predicted mean regression line but the mean value of -0.044 is not in fact significantly different from zero. The 'normal range' of the IPE can, therefore, be given as -0.45 to +0.45 . IPE values in renal stone disease, hyper- and hypoparathyroidism are also shown in Fig. 3. The separation between the different groups is reasonably satisfactory although there is some overlap between the stone and hyperparathyroid cases. For comparison, the simple plasma phosphorus values are shown in Fig. 4 and the uncorrected $P_{E}$ values in Fig. 5. It is clear that neither of these parameters discriminates as well as the IPE.

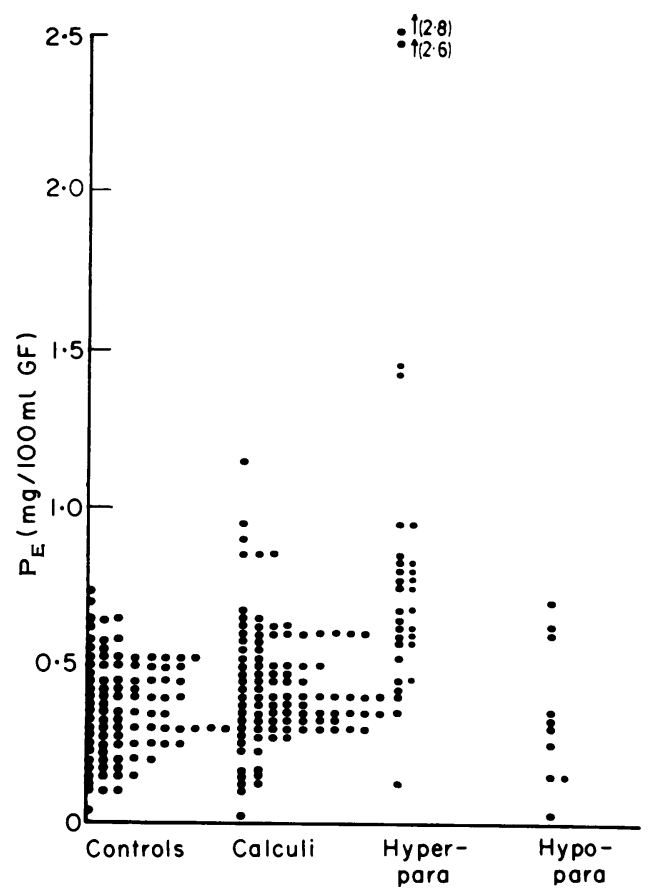

FIG. 4. Phosphorus excretion per $100 \mathrm{ml}$ of glomerular filtrate in the same four groups as Fig. 3.

\section{Conclusion}

For convenience in practice, we suggest that the IPE may be calculated as follows:

$$
\mathrm{IPE}=\mathrm{P}_{\mathrm{E}}-\frac{P_{\mathrm{p}}-2 \cdot 5}{2}
$$

The normal range of the value may be taken as $\pm 0 \cdot 5$.

\section{Discussion}

A weakness of the phosphate/creatinine clearance ratio on which our previous phosphate excretion index was based was that when it was regressed on plasma phosphorus, the latter value appeared in both axes of the regression, since plasma phosphorus was not only the independent variable but also the denominator in the ratio which constituted the dependent variable. Thus in regressing $C_{\mathrm{p}} / C_{\mathrm{cr}}$ on $P_{\mathrm{p}}$ we and all previous workers were in fact regressing $y / x$ on $x$. This 
would, of course, tend to produce an inverse correlation between $y$ and $x$ and to obscure the positive correlation which in fact exists between filtered load of phosphorus and urinary phosphorus excretion as demonstrated by the significant positive correlation we have obtained on recalculating the excretion data in a different way.

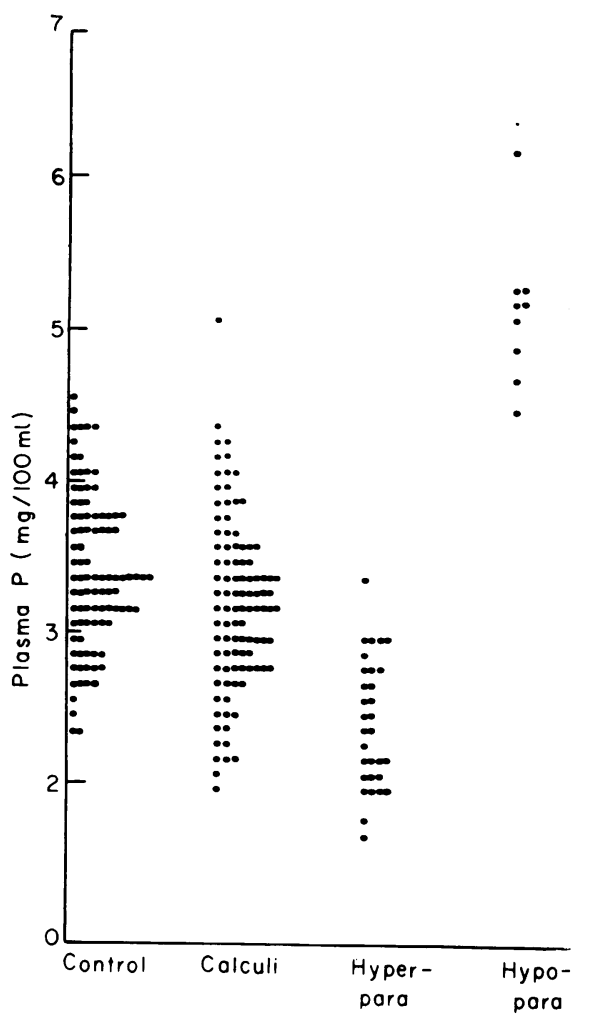

FIG. 5. Plasma phosphorus values for the same four groups as Figs. 3 and 4.

Another reason for recalculating the data in the way we have suggested is that it brings the mode of expressing phosphorus excretion into line with one which is becoming increasingly applied to other substances such as bicarbonate (Pitts, Ayer \& Schiess, 1949). We have also found it extremely appropriate for calcium excretion. The fact is that the plasma (or when appropriate the plasma water) concentration of a substance is the filtered load per $100 \mathrm{ml}$ of glomerular filtrate and that the ratio of this substance to creatinine in the urine multiplied by the plasma creatinine is the amount excreted per $100 \mathrm{ml}$ of GF (assuming that creatinine clearance measures GFR). These two values, both of which are very easily measured, can therefore be directly re- lated to each other. Moreover, despite theoretical objections voiced by Anderson \& Parsons (1963), expression of data in this way eliminates interindividual differences attributable to differences in glomerular filtration rate (whether due to variations in body size or to actual variations in renal function) and so eliminates what for many purposes is an irrelevant variable and allows comparison of excretion in individuals of very different sizes and even with very differing degress of renal function.

In a recent publication, Janse, van Gelderen \& Ruys (1966) have criticized the phosphate/ creatinine clearance ratio and PEI on the ground that there is no positive correlation between urinary phosphorus and plasma phosphorus. Inspection of their data on children shows, however, an error in their calculations which when correctly calculated reveal a positive correlation between urinary and plasma phosphorus as would be expected. Bijvoet (1967) has criticized the phosphate excretion index on the ground that the original slope of Lambert et al. (1947) on which it was based was itself inaccurate and should have been steeper. According to him, the PEI is valid up to plasma phosphorus levels of about $3.9 \mathrm{mg} / 100 \mathrm{ml}$ but yields false high values thereafter because the slope or urinary on plasmaco phosphorus becomes steeper at that point. His criticism, if valid, would be equally applicableto the index of phosphate excretion proposed in this paper. We suspect, however, that his criticism is unfounded since if it were correct our normal data would tend to fall above the mean regression line whereas as shown in Figs. 2 and 3 they tend if anything to fall below it. The answer to this problem depends upon what is in fact a 'normal' degree of parathyroid activity and we suggest that this is best defined by studying a random sample of normal people on free diets in the way we have done. We are aware that high phosphorus diets produce high indices and low phosphorus diets low indices but we believe these represent increased and decreased parathyroid activities respectively (Nordin \& Smith, 1965). The steeper rise of urine on plasma phosphorus produced by Bijvoet (1967) and others could be due to parathyroid stimulation produced by the phosphorus infusion.

It must be emphasized that no index of phosphate excretion can be a specific measure of parathyroid activity any more than the plasma calcium is a specific measure of parathyroid activity. We put this procedure forward as the best available simple method of estimating tubular reabsorption of phosphorus, which we believe is influenced more by parathyroid activity 
than by any other physiological variable. This is not to say, however, that there are not other factors (such as acid-base balance and congenital anomalies) which affect this process, just as there are many influences besides parathyroid hormone which determine plasma calcium.

\section{References}

Anderson, J. \& Parsons, V. (1963) The tubular maximal resorptive rate for inorganic phosphate in normal subjects. Clin. Sci. 25, 431.

BiJVoet, O.L.M. \& BloedSPIEgel (1967) Tubulair Maximum en Uitscheiding van Fosfaat. Dessain, Mechelen.

EDwards, N.A. \& Hodgkinson, A. (1965) Studies of renal function in patients with idiopathic hypercalciuria. Clin. Sci. 29, 327.

Harden, R.McG., Harrison, M.T. \& Alexander, W.D. (1963) Phosphate excretion and parathyroid function after radioiodine therapy and thyroidectomy. Clin. Sci. 25, 27.

Hodgkinson, A. (1963) Biochemical aspects of primary hyperparathyroidism. Clin. Sci. 25, 21.

Janse, H., van Gelderen, H.H. \& RuYs, J.H. (1966) Assessment of urinary phosphate excretion in normal and abnormal children. Arch. Dis. Childh. 41, 541.

Kyle, L.H., SchaAf, M. \& Canary, J.J. (1958) Phosphate clearance. Amer. J. Med. 24, 240.
Lambert, P.P., van Kessel, E. \& Leplat, C. (1947) Etude sur l'elimination des phosphates inorganiques chez l'homme. Acta med. scand. 128, 386.

Milne, M.D., Stanbury, S.N. \& Thomson, A.E. (1952) Observations on Fanconi Syndrome and renal hyperchloraemic acidosis in adults. Quart. J. Med. 21, 61.

Nordin, B.E.C. (1964) Tests for parathyroid function. Postgrad. Med. 35, 42.

NordIN, B.E.C. (1961) Biochemical aspects of parathyroid function and hyperparathyroidism. Advanc. clin. Chem. 4, 275.

Nordin, B.E.C. \& Fraser, R. (1954) The effect of intravenous calcium on phosphate excretion. Clin. Sci. 13, 477.

Nordin, B.E.C. \& FraSER, R. (1960) Assessment of urinary phosphate excretion. Lancet, i, 947.

Nordin, B.E.C. \& SMITH, D.A. (1965) Diagnostic Procedures in Disorders of Calcium Metabolism. Churchill, London.

PitTs, R.F., Ayer, J.L. \& Schiess, N.A. (1949) The renal regulation of acid base balance in man. III. The reabsorption of bicarbonate. J. clin. Invest. 28, 35 .

ReYnolds, T.B., Lanman, H. \& Tupikova (1960) Maximum tubular reabsorption of phosphate (TmP) in hyperparathyroidism. J. clin. Endocr. 20, 1136.

SMiTH, D.A. \& Nordin, B.E.C. (1964) The effect of a high phosphorus intake on total and ultrafilterable plasma calcium and on phosphate clearance. Clin. Sci. 26, 279.

Thomas, W.C., Connor, T.B. \& Morgan, H.G. (1959) Medical progress: diagnostic considerations in hypercalcaemia with discussion of various means by which such a state may develop. New Engl. J. Med. 260, 591.

\title{
The Achilles tendon reflex as an index of thyroid function
}

\author{
GeORge Nuki R. I. S. BAYLISS
}

Westminster Hospital and Medical School, London

THIS PAPER is dedicated with affection to John McMichael who so rightly taught one of us that in the practice of medicine mensuration was often the great corrective to that important but potentially misleading entity known as 'clinical impression'.

\section{Introduction}

In 1884 William Ord reported that the tendon reflexes elicited on clinical examination were prolonged in patients with myxoedema. Not until 40 years later was this prolongation recorded graphically (Chaney, 1924); the converse shortening of the reflex time in thyrotoxic patients was first demonstrated in 1929 (Fournier). Subsequently a number of workers using various recording devices have measured the tendon reflexes in patients with thyroidal dysfunction (Harrell \& Daniel, 1941 ; Lambert et al., 1951 ; Lawson, 1958 ; Gilson, 1959 ; Sharpe, 1961 ; Fogel et al., 1962 ; Fejer \& Kun, 1963 ; Sherman, GoldG berg \& Larson, 1963 ; Smart \& Robson, 1963 ; Moulopoulas, Koutras \& Kralios, 1964; Reinfrank et al., 1967).

Today two main techniques are used, the photomotogram (Gilson, 1959) and the kinemometer (Lawson, 1958). In the former the movement of the sole of the foot, after percussion of the Achilles tendon, interrupts a light path which transmits a signal via a photo-electric transducer to an electrocardiographic (ECG) machine and writes a tracing as shown in Fig. 1(a). Thyroidal function has been assessed from either the 'half-relaxation time' or the 'relaxation time' (Fig. 1a). The kinemometer is an electromagnetic device. A magnet is attached to the sole of the patient's foot and on percussion this moves into an electrical field inducing a current which is transmitted to an ECG machine. A tracing is written as shown in Fig. 1(b). The time from stimulation to the end of contraction or from maximal contraction to maximal relaxa- 